\title{
Assessment of medical equipment maintenance management: proposed checklist using Iranian experience
}

\author{
Morteza Arab-Zozani ${ }^{1}$, Ali Imani ${ }^{2}$, Leila Doshmangir ${ }^{3}$, Koustuv Dalal ${ }^{4,5}$ and Rona Bahreini $i^{6^{*}}$ (D)
}

\author{
*Correspondence: \\ bahreiny6886@gmail.com \\ ${ }^{6}$ Tabriz Health Services \\ Management Research \\ Center, Iranian Center \\ of Excellence in Health \\ Management, Student \\ Research Committee, School \\ of Management and Medical \\ Informatics, Tabriz University \\ of Medical Sciences, Tabriz, \\ Iran \\ Full list of author information \\ is available at the end of the \\ article
}

\begin{abstract}
Background: Effective maintenance management of medical equipment is one of the major issues for quality of care, for providing cost-effective health services and for saving scarce resources. This study aimed to develop a comprehensive checklist for assessing the medical equipment maintenance management (MEMM) in the Iranian hospitals.
\end{abstract}

Methods: This is a multi-methods study. First, data related to factors which affect the assessment of MEMM were collected through a systematic review in PubMed, ProQuest, Scopus, Embase, and web of science without any time limitation until October 2015, updated in June 2017. Then, we investigated these factors affecting using document review and interviews with experts in the Iranian hospitals. In the end, the results of the first and second stages were combined using content analysis and the final checklist was developed in a two-round Delphi.

Results: Using a combination of factors extracted from the systematic and qualitative studies, the primary checklist was developed in the form of assessment checklists in seven dimensions. The final checklist includes 7 dimensions and 19 sub-categories: "resources $=3$," "quality control $=3$,"'information bank $=4$," education $=1$,"'service $=3$," "inspection and preventive maintenance $=2$ " and "design and implementation $=3$."

Conclusions: Developing an assessment checklist for MEMM provide a comprehensive framework for the proper implementation of accurate assessment of medical equipment maintenance. This checklist can be used to improve the profitability of health facilities and the reliability of medical equipment. In addition, it is implicated in the decision-making in support of selection, purchase, repair and maintenance of medical equipment, especially for capital equipment managers and medical engineers in hospitals and also for the assessment of this process.

Keywords: Hospital, Medical equipment, Medical devices, Maintenance management, Assessment

(c) The Author(s) 2021. This article is licensed under a Creative Commons Attribution 4.0 International License, which permits use, sharing, adaptation, distribution and reproduction in any medium or format, as long as you give appropriate credit to the original author(s) and the source, provide a link to the Creative Commons licence, and indicate if changes were made. The images or other third party material in this article are included in the article's Creative Commons licence, unless indicated otherwise in a credit line to the material. If material is not included in the article's Creative Commons licence and your intended use is not permitted by statutory regulation or exceeds the permitted use, you will need to obtain permission directly from the copyright holder. To view a copy of this licence, visit http://creativecommons.org/ licenses/by/4.0/. The Creative Commons Public Domain Dedication waiver (http://creativecommons.org/publicdomain/zero/1.0/) applies to the data made available in this article, unless otherwise stated in a credit line to the data. 


\section{Background}

Today's modern hospital is highly dependent on various types of medical equipment to assist in the diagnosis, monitoring and treatment of patients. It is impractical to provide health services without them $[1,2]$. Medical equipment deals with patient care including ranging from small and simple devices to complex and big devices. This ranking can be found in different types of hospitals and primary care settings [3]. According to the studies conducted in Iran, about one-third of the costs of setting up and equipping the hospital is allocated for purchasing medical equipment [4]. Therefore, it should be maintained in good working condition and higher safety level to prevent from injuries occurred in patients as well as in users [5].

The maintenance of medical equipment is important for reducing dispatch costs, reducing patient dissatisfaction, timely patient treatment, and reducing mortality and risks during patients care [4]. It is an integral part of the life cycle of the device. Usually, much more money is spent on maintaining equipment over than on its procurement [6]. Maintenance is defined as any action which helps hospitals to provide an adequate level of service and to protect or promote the performance of their equipment to operate regularly and efficiently. Therefore, maintenance management is a fundamental aspect of hospital management [7].

Good maintenance management to have well planned and implemented programs that hospitals can minimize breakdowns or failures of the medical device. This is particularly critical in developing countries for providing good healthcare services and saving scarce resources and alternatives. The equipment maintenance management of the hospital not only makes them easily accessible when needed but also increases their reliability and reduces their failure rate $[4,8]$. Despite the importance of maintenance, there was no clear system of maintenance. The guidelines are not properly performed in many countries including Iran. In addition, there is a lack of information about the assessment and evaluation of medical equipment decisions [9].

A survey indicated that nearly $60 \%$ of the total cost of a hospital involves medical equipment [8]. Wang et al. have demonstrated that the most common cause of medical equipment downtime is poor maintenance, planning, and management [3]. One study indicates that nearly $1 \%$ of the total hospital budget is spent on maintenance costs [10]. The literatures have indicated that a 500-bed hospital spends typically around $\$ 5$ million/year [6]. A study of world health organization (WHO) has shown that nearly half of medical devices in developing countries are operated incorrectly or are not maintained properly due to inappropriate management policy. On the other hand, the potential to manage and maintain medical equipment in these countries remains rather weak [11].

Medical equipment plays a significant role in the hospital system; hence, the purchase, maintenance and replacement of medical equipment are key factors in hospitals to implement medical care service. Thus, to assure the quality of healthcare delivery medical devices, use-safety assessment of the maintenance management in hospitals is imperative [12]. To achieve these objectives, hospitals must develop assessment checklists which identify the performance status of medical equipment maintenance. It is essential for managers and engineers, not only to enhance hospital capability but also to predict the risks related to sudden failure. Given the lack of single and comprehensive checklists for maintenance management, the purpose of the current research is to design 
and develop assessment checklists for medical equipment maintenance management (MEMM).

\section{Results}

Of 309 potentially relevant articles searched, 29 articles were included in this systematic review. Finally, 89 factors were identified that affect the medical equipment maintenance management. These factors categorized based on MOHME framework [13]. Five of the factors were found related to resources, 12 factors related to service, 4 factors related to education, 15 of these factors regarding to quality control, 19 factors related to inspection, 12 factors related to information bank and 22 factors was dedicated to management [14].

The results of qualitative study were categorized into seven main themes (resources, quality control, documentation, education, service, inspection and preventive maintenance (IPM), designing and implementation) [15].

Based on the findings of the first and second steps, a medical equipment maintenance management assessment checklist was developed as follows (Table 1).

The checklists have seven dimensions, each of which includes sub-categories, such as the provision of variety of financial, human and physical resources, which means physical resources to provide a safe and secure environment equipped with the necessary facilities. Human resources refer to the provision and allocation of experienced and skilled manpower based on need. Financial resources also include the allocation of sufficient and necessary funds and budgets, which should be based on the goal and be allocated to priority goals according to the operational plan of the medical engineer unit.

The dimension of quality control tests in the three sub-categories of safety test, performance test and calibration refer to all technical tests that require special equipment and are of special importance for the health of the patient and staff. The Inspection and Preventive Maintenance Item refers to the importance and priority of PM than repairing and assessing the user and performance of personnel. In this section, there are topics such as periodic inspections, development of maintenance standards, the existence of external supervisors, and the existence of written and comprehensive guidelines.

In the field of information bank, all activities related to the process of documentation and identification of medical equipment is listed. In the training section, both technical and user training for medical engineers and users are mentioned. The sub-categories of the service sector include after-sales service, repair and maintenance contracts, outsourcing of the decommissioning process, and so on. The last dimension is design and implementation, which refers to issues such as defining the level of user access, organizing joint committees, establishing inter-sectorial communication, policy development, purchasing medical equipment based on needs, and so on.

The scoring method is in three categories of zero, one and two. If the item meets the criteria, score 2, in case of partial compliance, one score and in case of mismatch, no points are awarded. For some items, one score is not included. That is, only two matching or mismatch modes are applicable and no intermediate states. Part of the checklist is about data collection that depending on the nature of the item, the collection method involves interview, observation and documentation review. Thus, the interview will 


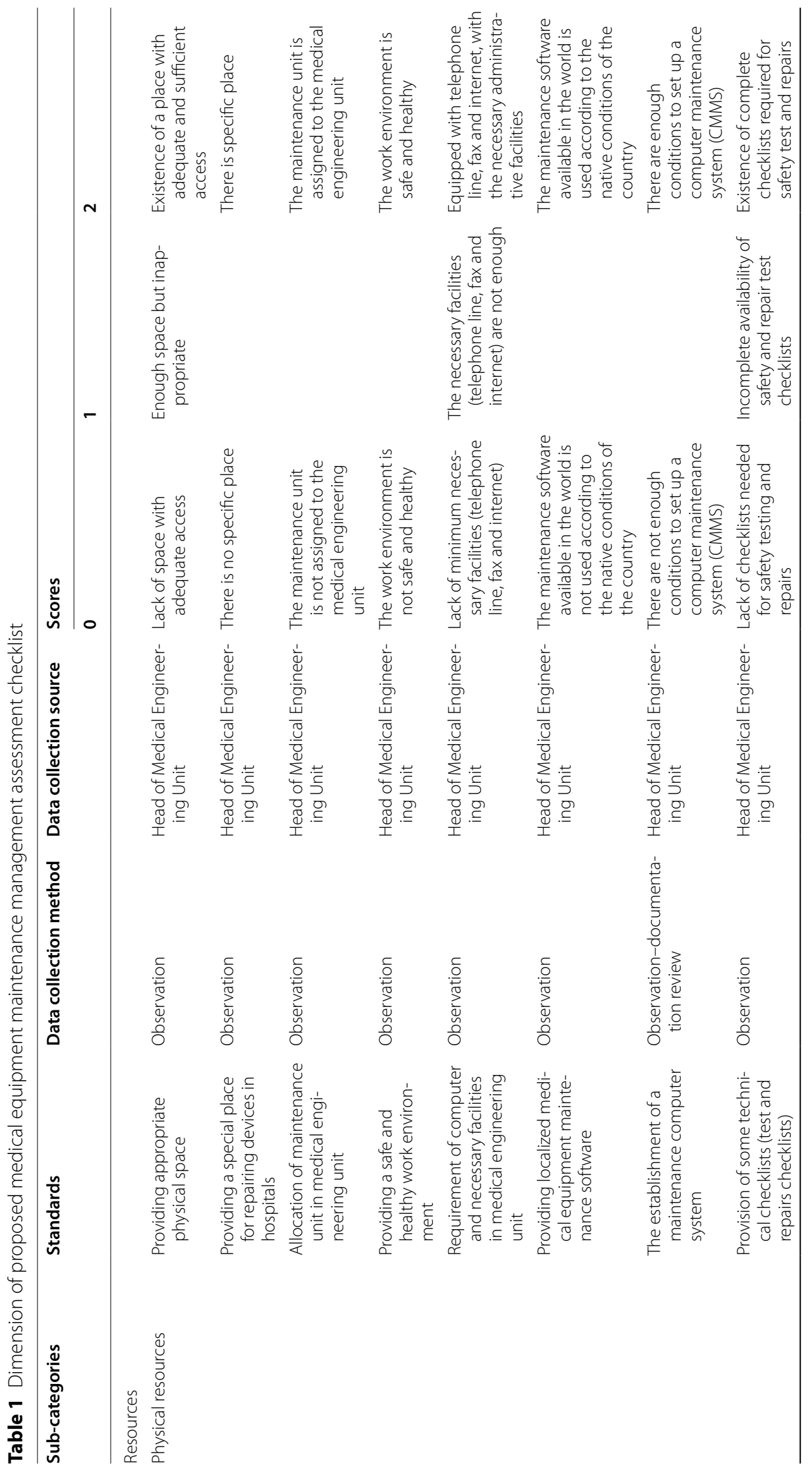




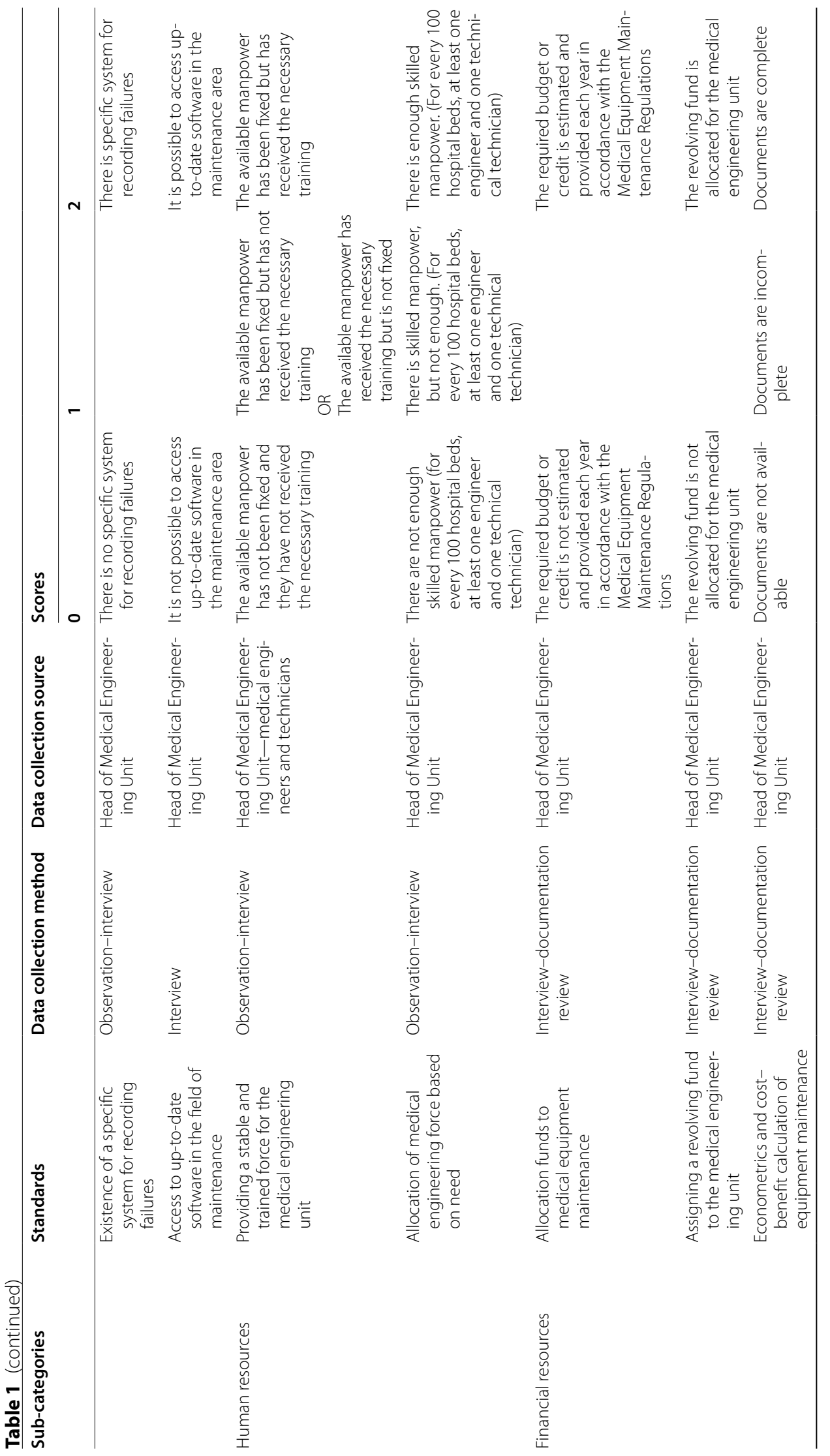




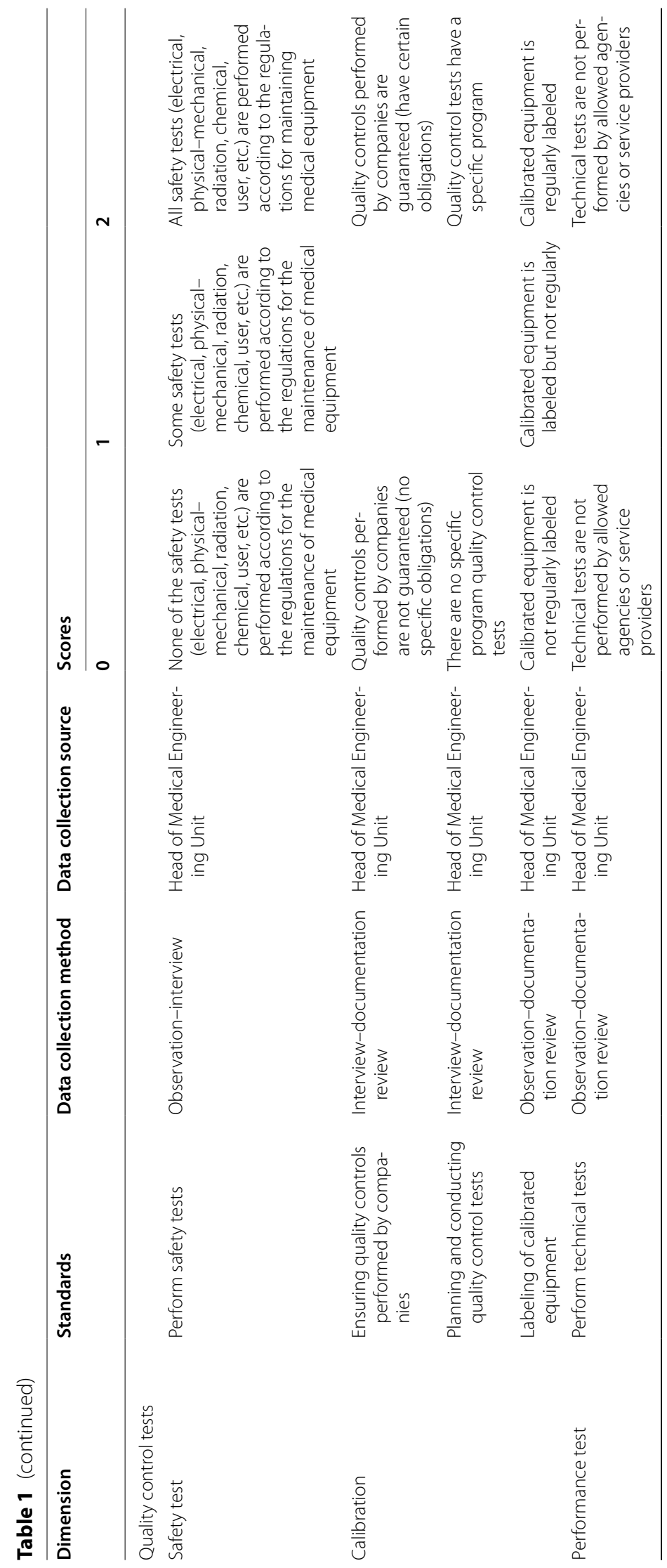




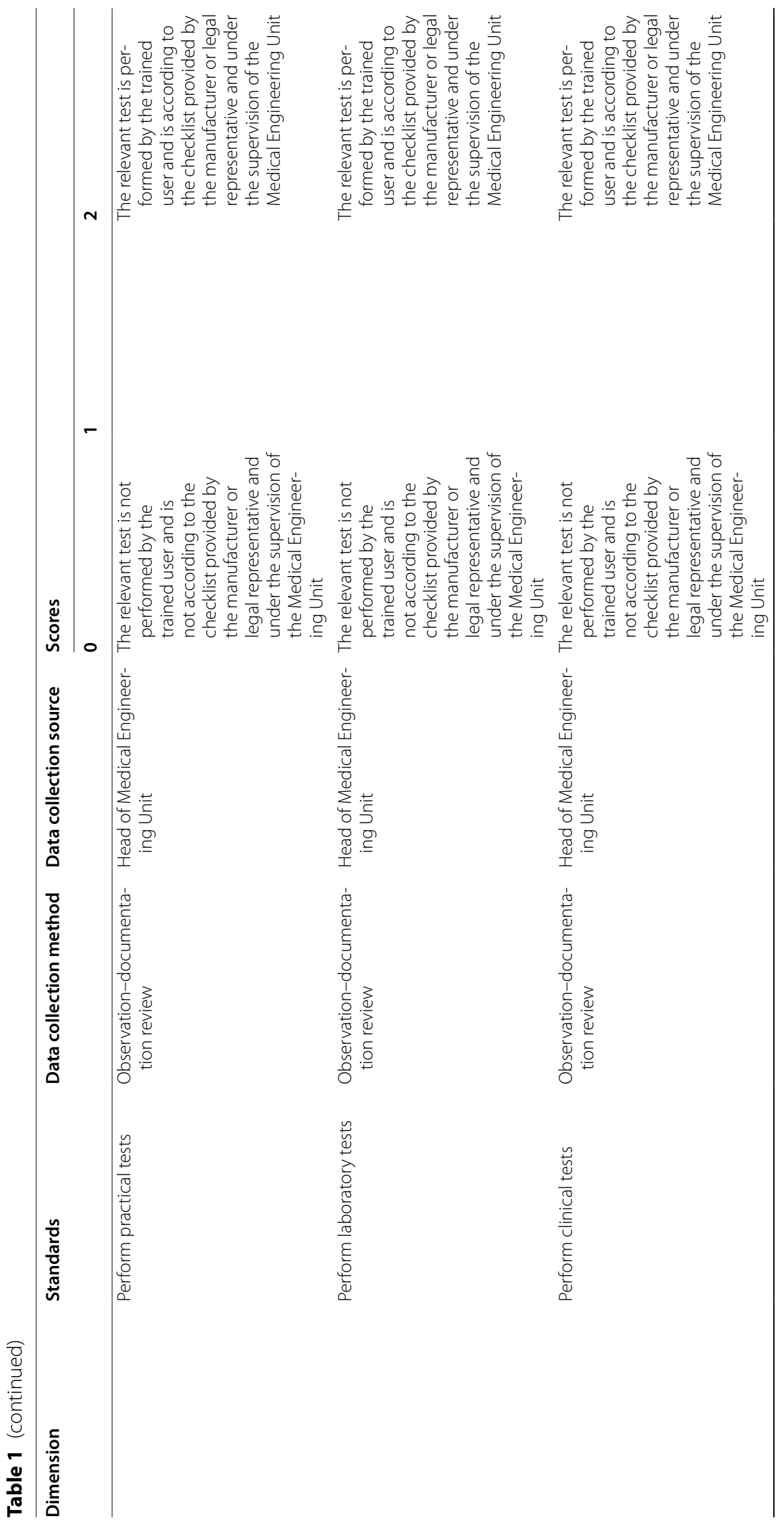




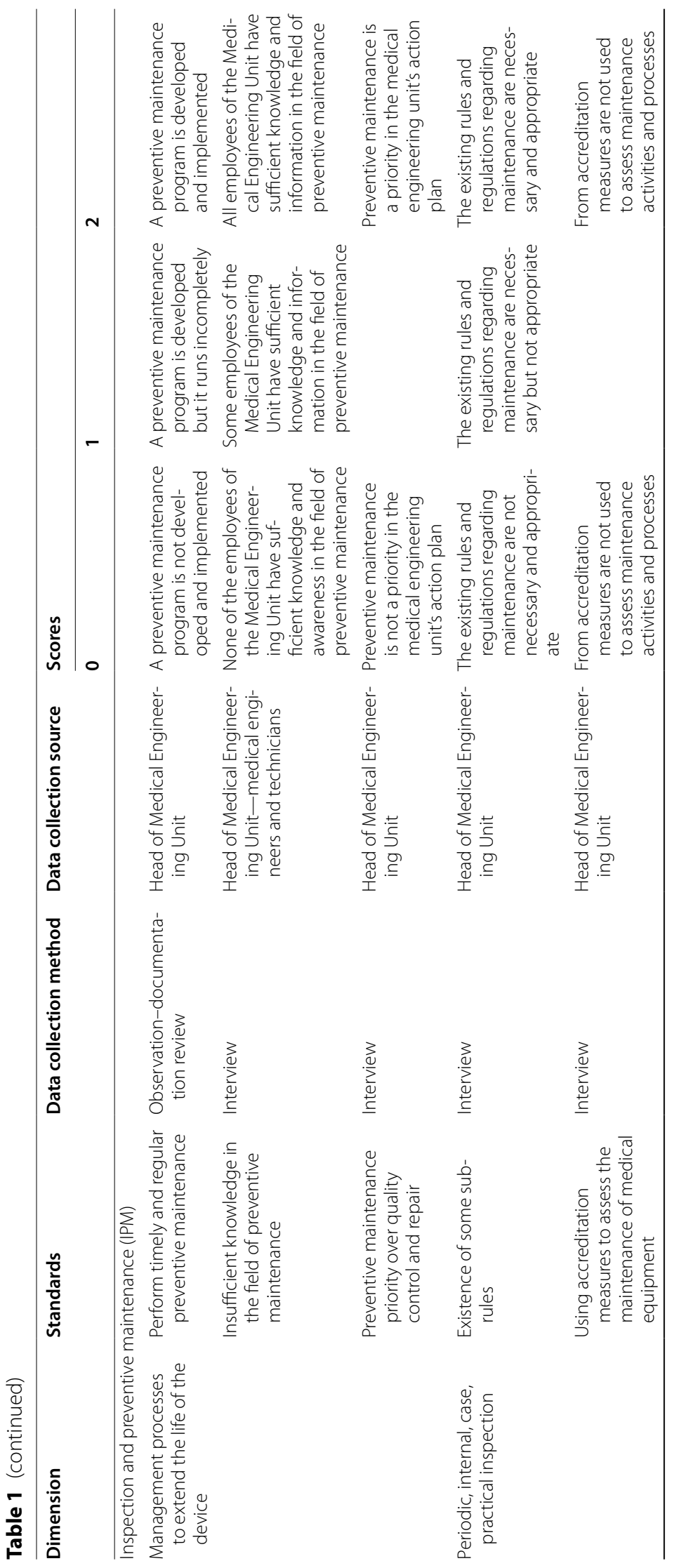




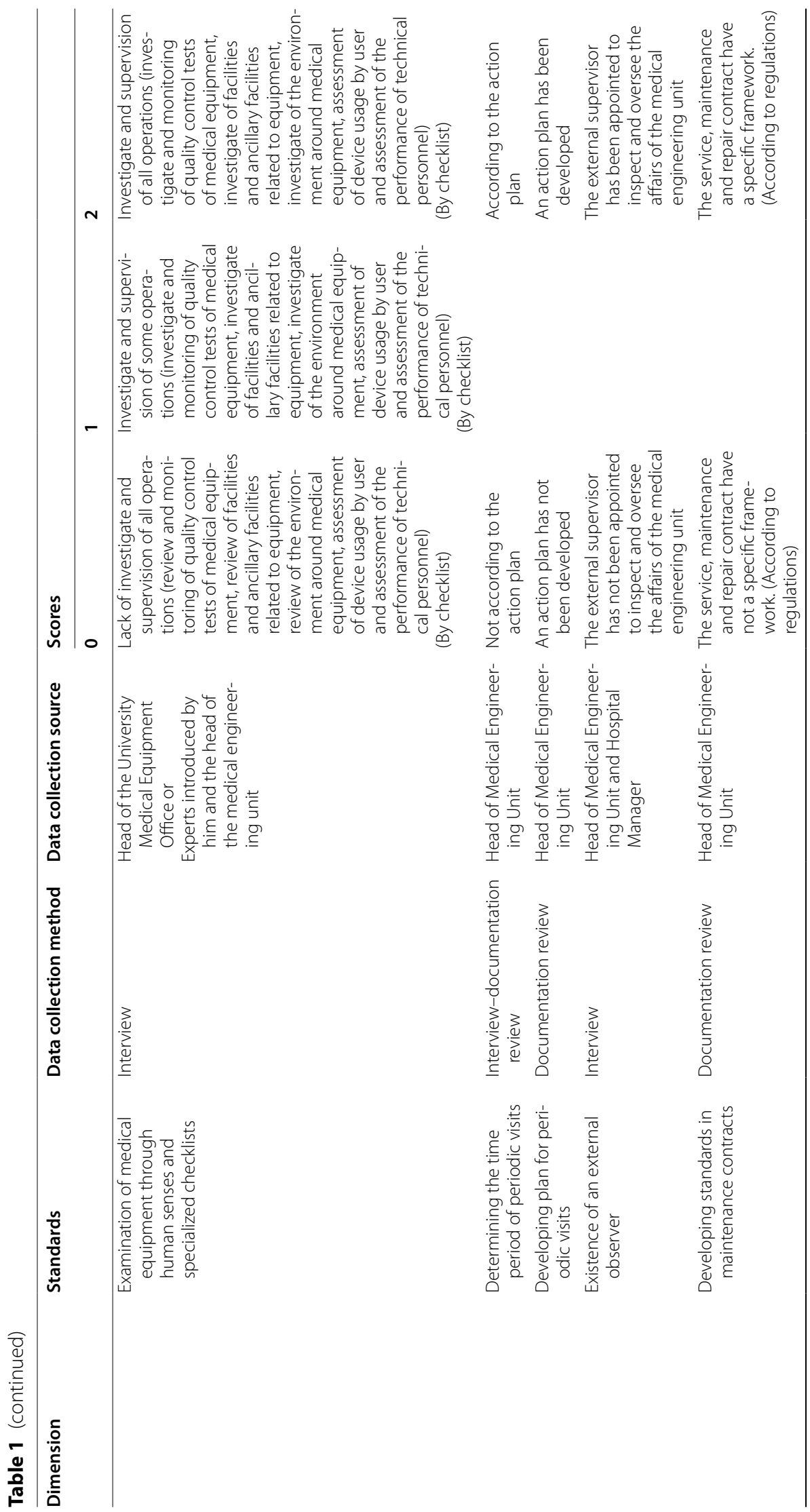




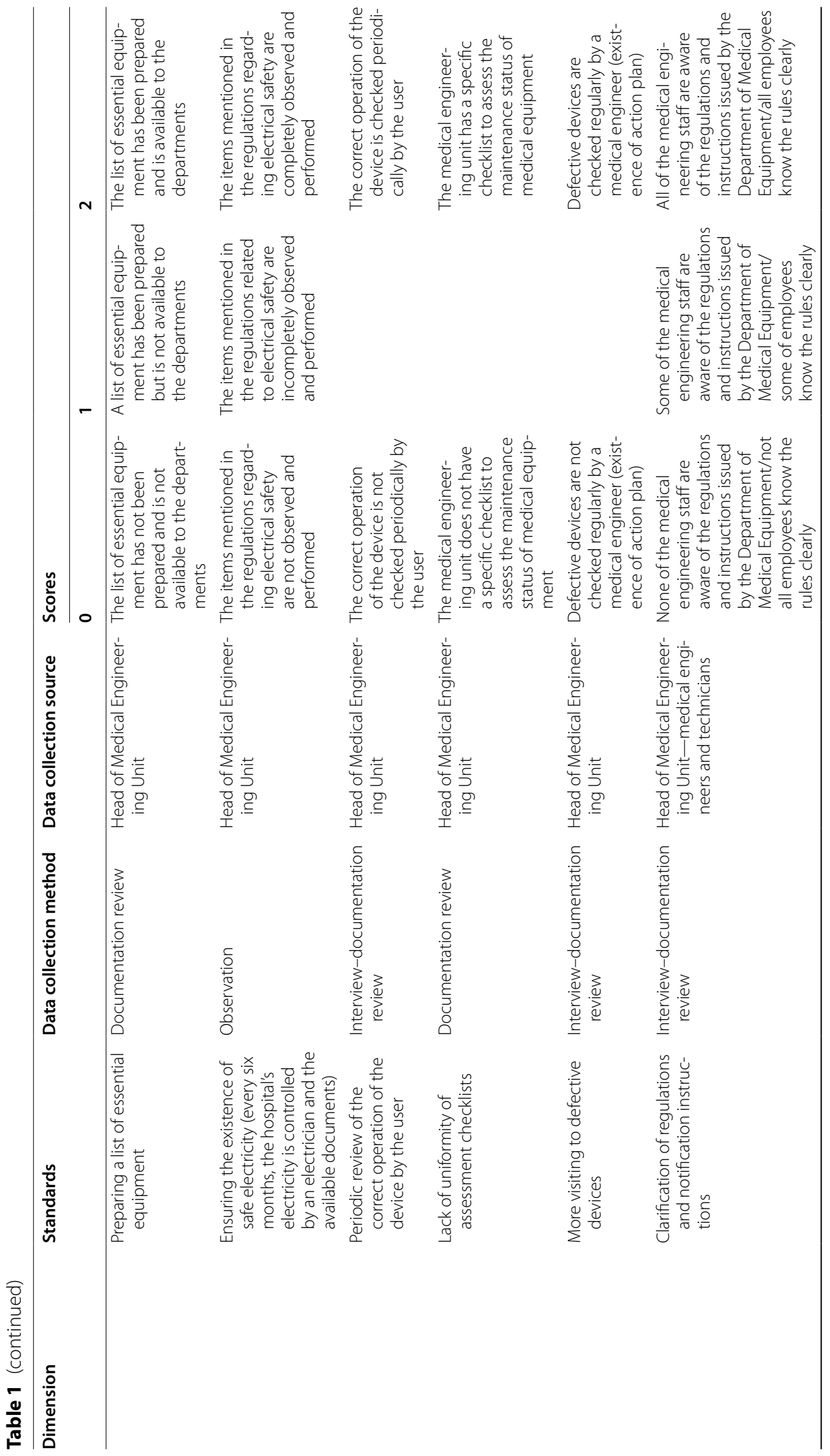




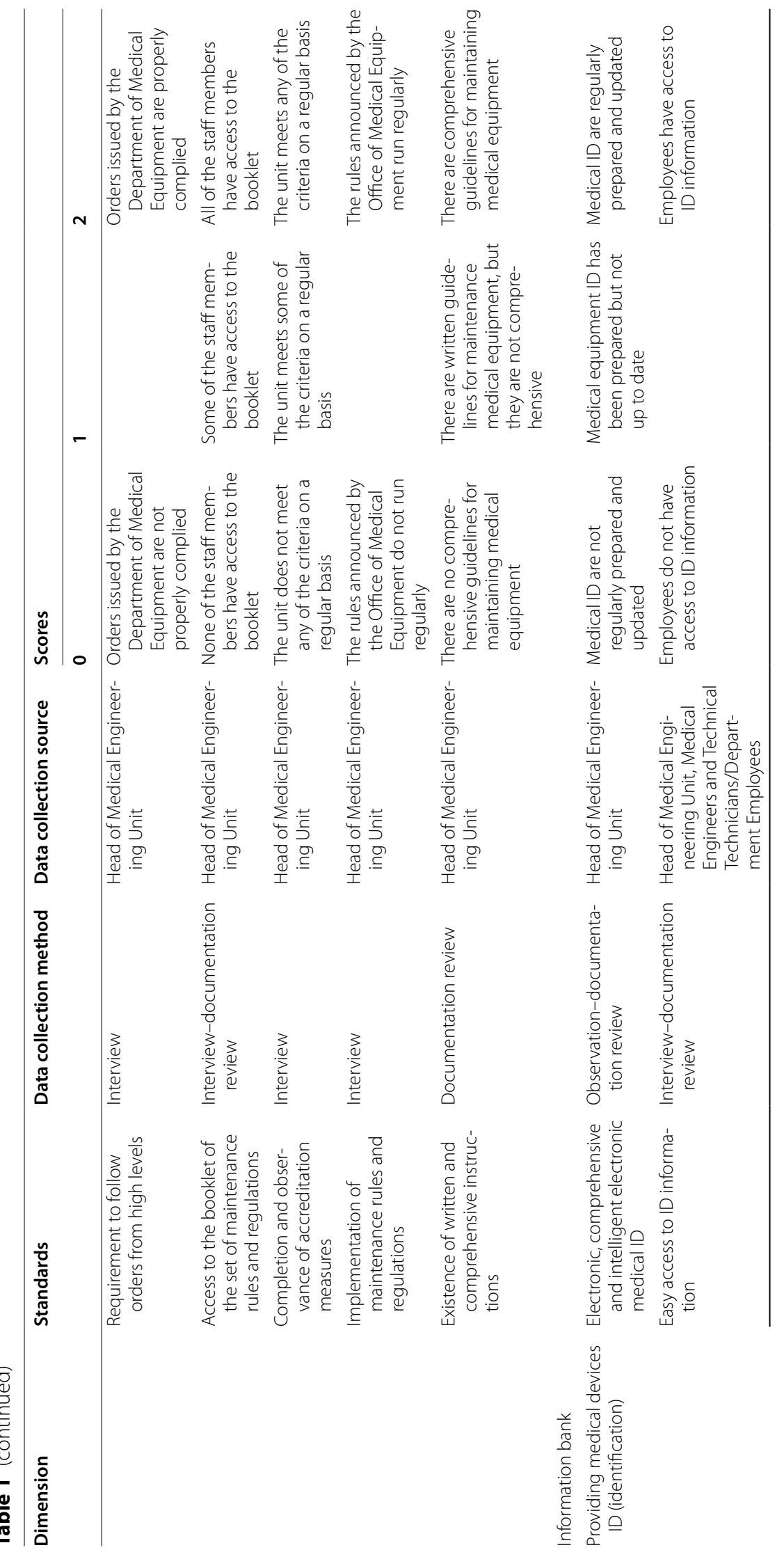




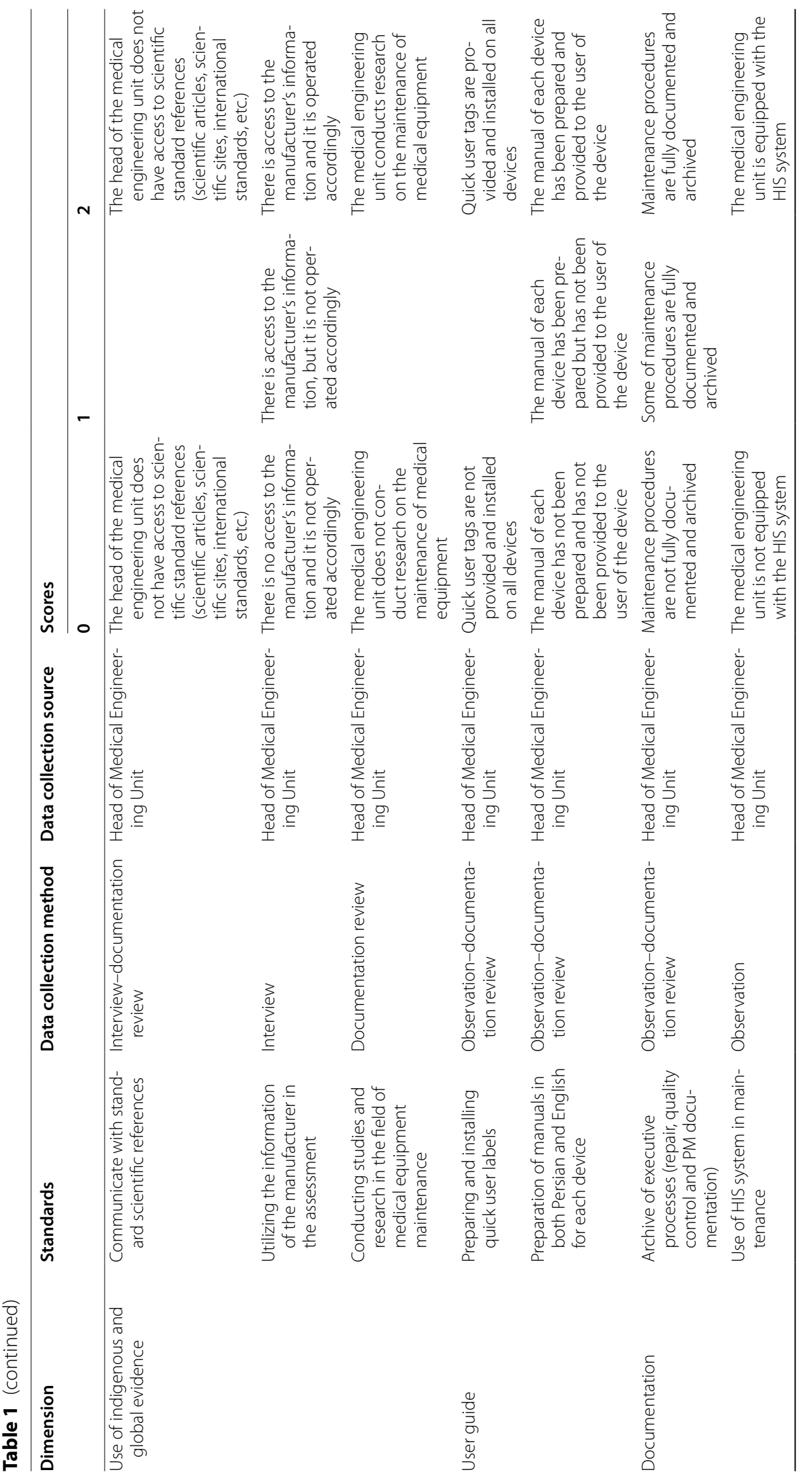




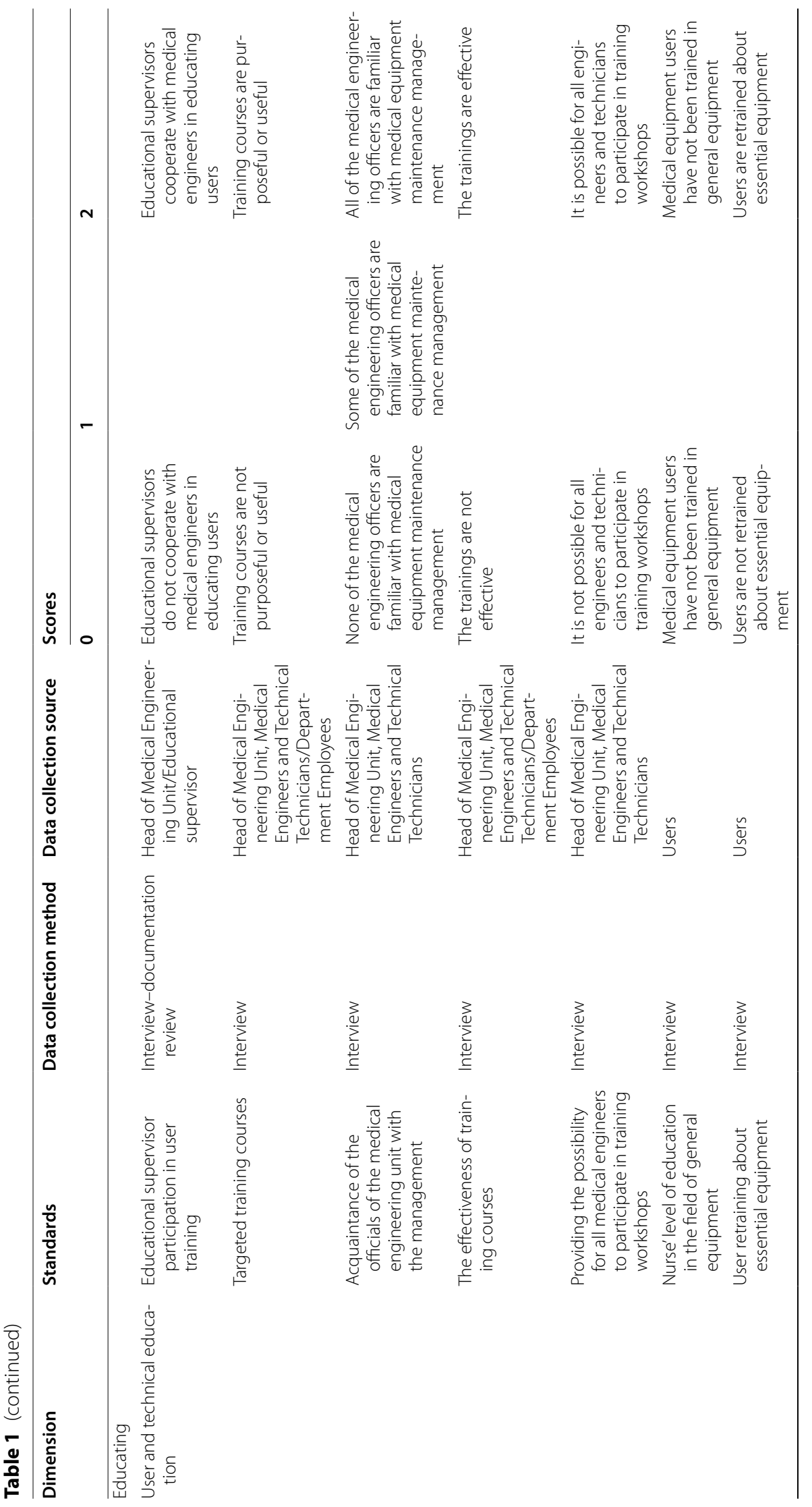




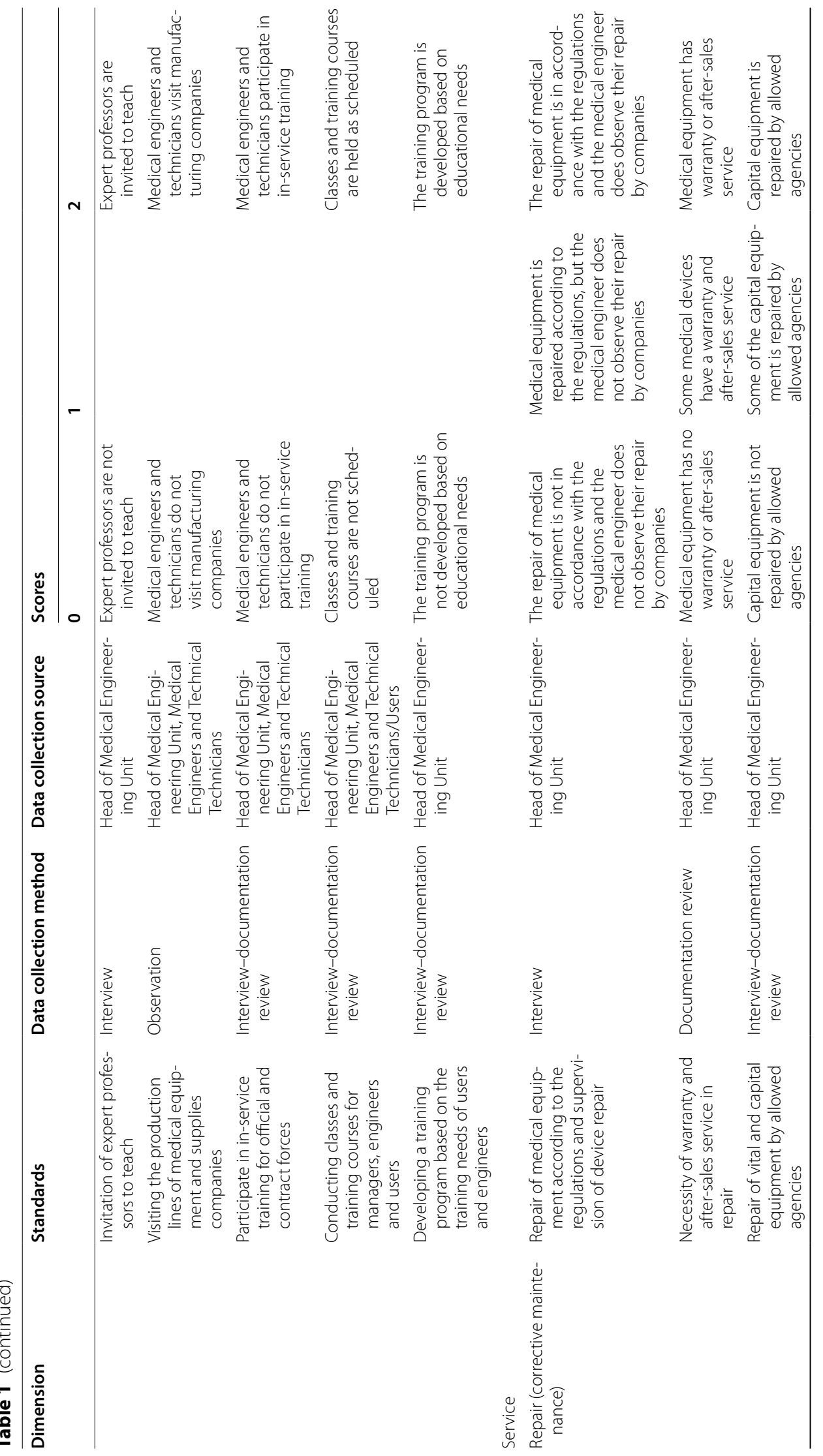




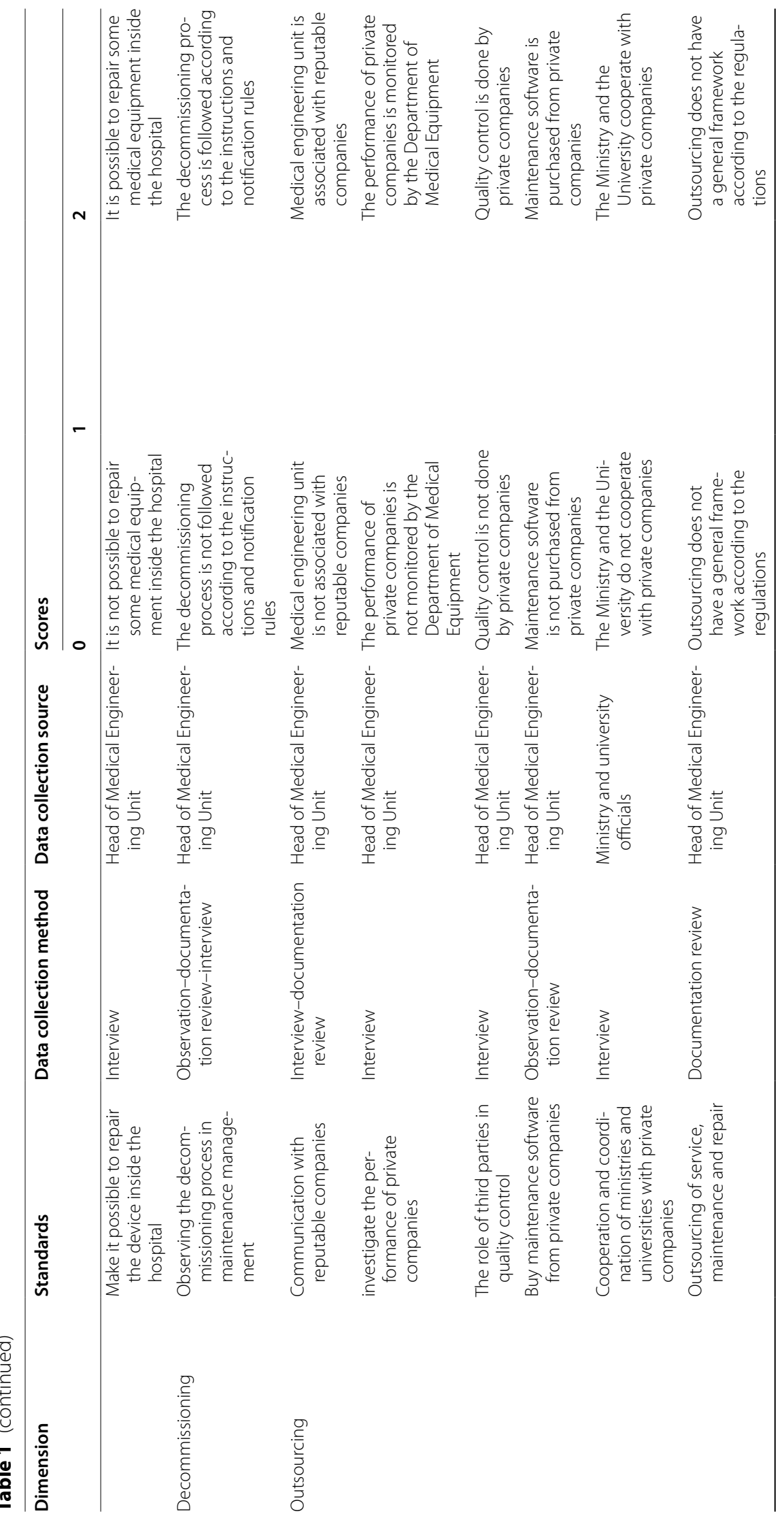




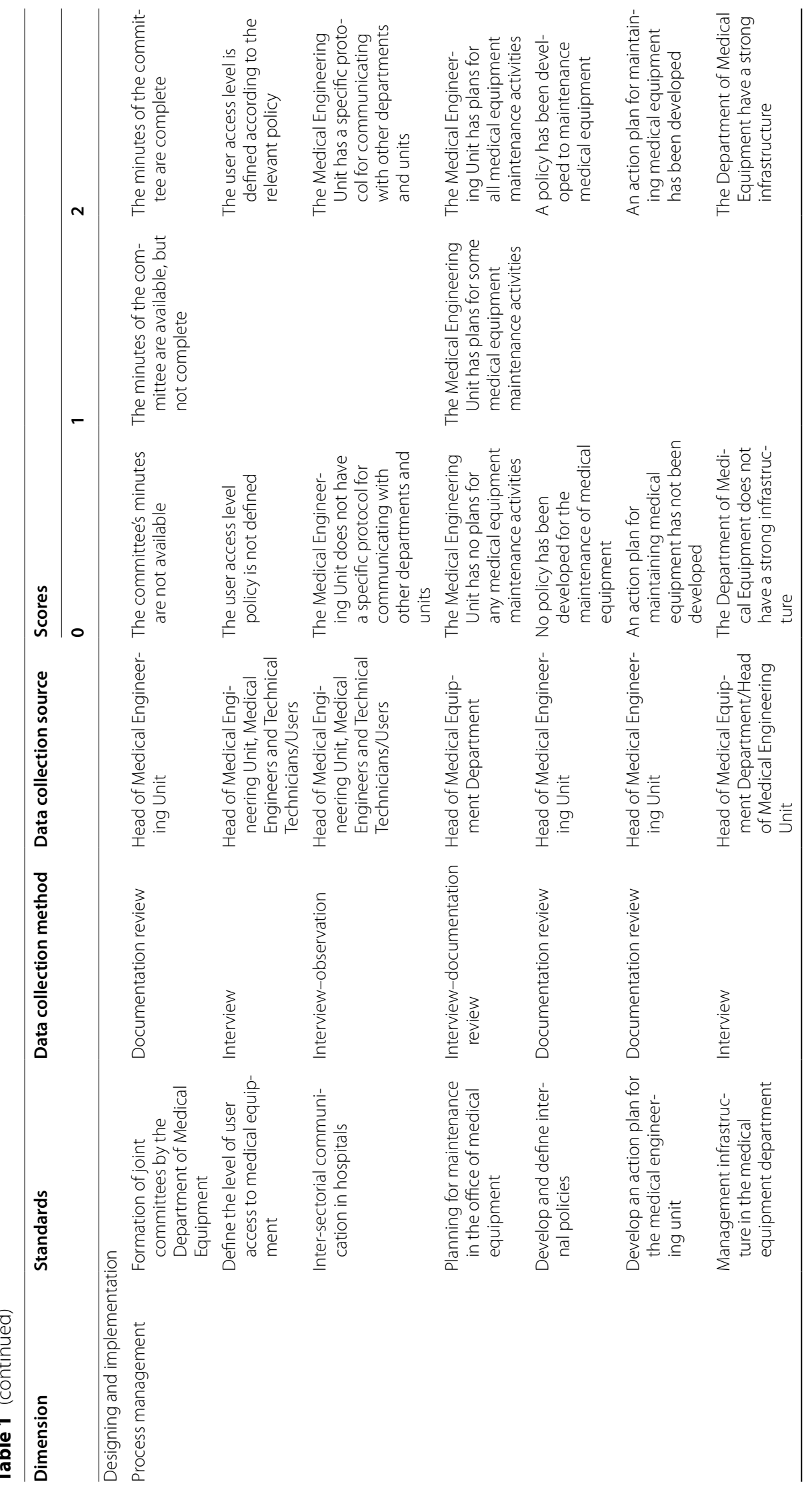




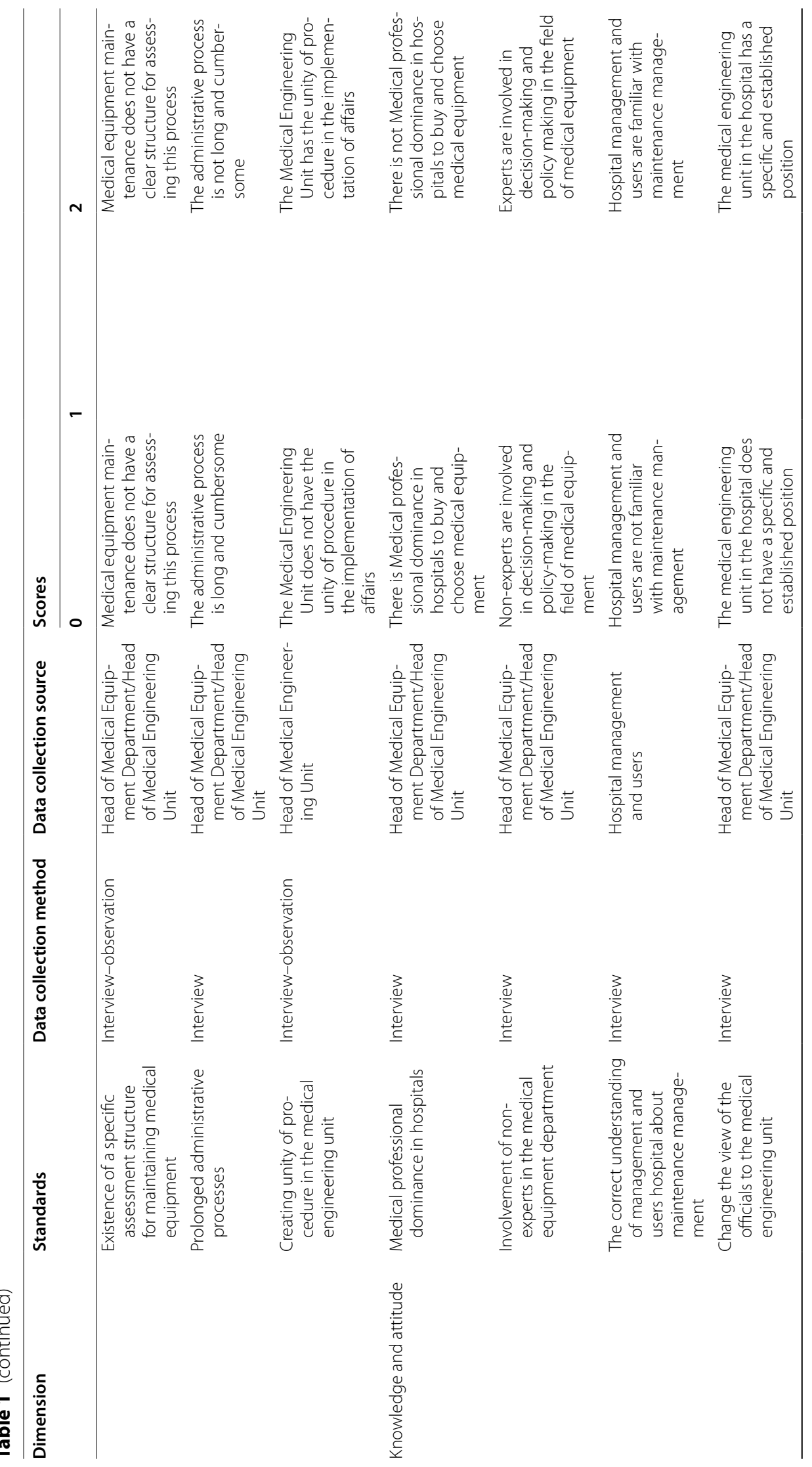




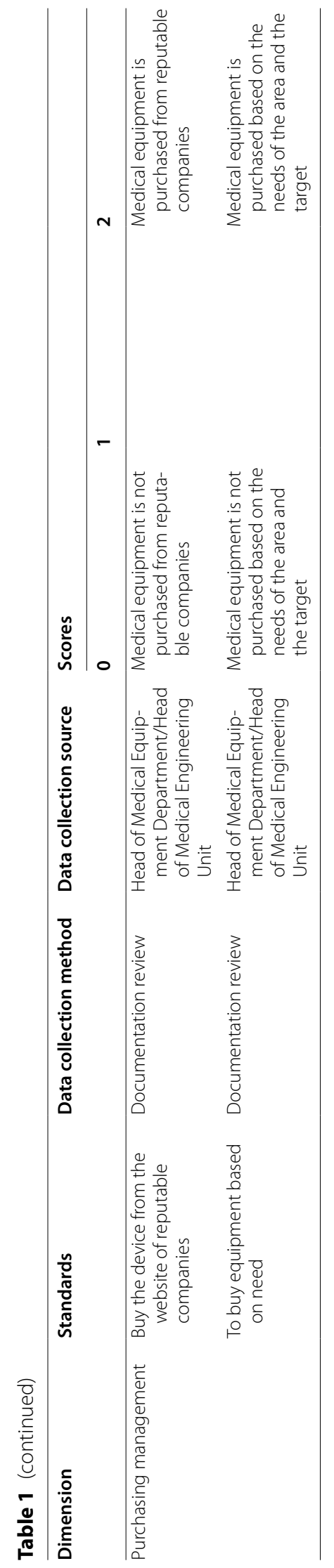


be used if we are looking for the views and attitudes of stakeholders. Dimensions that require documentation will be assessed through documentation review. The observation method is also for assessing physical items.

\section{Discussion}

In the field of medical equipment maintenance management, there is no single and standard checklist that includes all hospitals in the country. The only available checklists include accreditation measures that generally assess the tasks and activities of the medical engineering unit. Since the issue of maintenance management includes a wide variety of topics, and in the low- and middle-income countries, there is major weakness in this regard, so we decided to design a checklist for uniformity and accurate and comprehensive assessment using Iranian context. The Departments of Medical Equipment of some provinces in Iran have designed a checklist natively for its affiliated hospitals, the dimension and method of which are different. For example, the maintenance management evaluation checklist of Tabriz Medical Equipment Office includes 15 indicators (technical force, medical engineering unit, medical equipment ID, quality control tests, PM, training, medical equipment and spare parts storage, service and maintenance contract, the existence of purchase process, the existence of decommissioning process, the existence of recall system and reporting of adverse events, ensuring sound electricity, implementing a continuous maintenance improvement process, familiarizing with the general administration's rules and website, management and allocating a separate budget for maintenance).

According to the medical equipment maintenance management criteria of the MOHME, some of these dimensions can be merged into one dimension and some can be separated. In addition, each of the indicators and sub-indicators can be expanded. That is, not all maintenance management issues are addressed. The scoring and classification of dimensions in this checklist does not have a specific standard and does not include all dimensions of maintenance according to the maintenance criteria of the MOHME and is generally designed.

Herrera-Galán [16] evaluated the performance of the maintenance function through management audits and their implementation in five hospitals. The aspects evaluated include equipment availability, response to a service request, monitoring and control of biomedical equipment, staff training, quality of work executed by the maintenance technicians, the workload of maintenance technicians, control of the work executed by the maintenance technicians, the effectiveness of annual maintenance planning and department performance. The results of this research show that the audit technique is a valuable checklist in the performance assessment of a hospitals. The application of the proposed method evidenced that the most critical component in the results of a management audit is the human resource [16].

An effective medical equipment maintenance program consists of three main elements. (1) Identifying the medical devices that need to maintenance program by the Ministry of Health. (2) Financial management, personal management, performance monitoring, operational management and performance improvement. (3) Proper implementation of the maintenance program. These three elements are also considered in the 
designed checklists in different dimensions such as resources, designing and implementation [17].

The maintenance and its management constitute a checklist that ensures the equipment performance. There exist four criteria in which the hospitals coincide that they should improve, even though each of them in different measure and sub-criterion. These criteria are an organization of maintenance; human resources; planning, programming and control of the maintenance and corrective maintenance. These criteria are among the sub-categories of maintenance management assessment checklists [18].

Amerion et al. [19] identified effective factors on the MEMM in a military hospital. Among effective factors on the MEMM, 26 components were extracted. User training components, human resources, commitment and the experience of users, the foreign exchange market, periodic visits, and trade name were the most important components which had more than $75 \%$ of the relative abundance. According to the results, factors with high importance on the management of medical equipment maintenance should be supported by the center's directors. Attention to the use of these components can reduce maintenance costs, and therefore, increase the life of medical equipment. User training and human resources are the two main dimensions of this checklist [19].

According to the current results, documentation and service are two dimensions of MEMM. The problems of some hospitals in MEMM were introduced from the aspects of maintenance time, maintenance record, maintenance service and selfmaintenance. Some measures were proposed including simplifying maintenance process through PDCA, information maintenance record, cooperating with the thirdparty maintainer and establishing self-maintenance team, so that precision and information medical equipment management can be realized to maximize the benefit of medical equipment management [20].

The medical equipment requires maintenance (both scheduled and unscheduled) during its useful life. The medical equipment maintenance process should be planned, implemented, monitored, and improved continually. This process requires careful supervision by healthcare administrators, many of whom may not have the technical background to understand all of the relevant factors. Maintenance management is the most important function in overall medical equipment management. In this regard, implementation of appropriate maintenance strategies requires the following types of resources: human resources, material resources, financial resources and documentation. Our findings also point to the importance of these resources [21].

We need a comprehensive assessment checklist that covers all aspects of medical equipment maintenance management in hospitals. In this regard, the identification of influential factors is essential. Eighty-nine factors were identified that affect MEMM. Five of the factors were found related to resources item, 12 factors related to service, 4 factors related to education, 15 of these factors regarding quality control, 19 factors related to inspection, 12 factors related to information bank and 22 factors were dedicated to management. These factors are implicated in decision-making in support of selection, purchase, repair and maintenance of medical equipment, especially for capital equipment managers and medical engineers in hospitals and also for the assessment of this process. Identification and classification of influential factors can 
be of help for raising critical alerts about the types of equipment more prone to maintenance problems [14].

\section{Strengths and limitations}

In our knowledge, this study is the first comprehensive study of-its-kind addressing all of the factors affecting an effective and efficient MEMM. It offers comprehensive checklists for assessing the status of MEMM. In addition, the present compiled checklist is the result of multi-method research in such a way that its components are determined through systematic review and obtaining the views of experts and specialists in this field. This indicates the validity and comprehensiveness of the checklists developed.

Lack of enough information concerning the concept of maintenance management, lack of specific guidelines and instructions were the most notable limitations.

\section{Conclusion}

Effective maintenance management of medical devices increases the efficiency and productivity of health technology resources, which is especially important when resources are limited. This allows patients to access medical equipment that can provide an accurate diagnosis, effective treatment, or appropriate rehabilitation. Several factors affect the management of medical equipment maintenance, and it is important to follow each of them to improve the performance of devices and provide medical services to patients. Therefore, before designing an assessment checklist, we need to consider a specific framework for the maintenance management process to include all maintenance activities. The medical equipment maintenance management assessment checklists allow for the timely identification of deficiencies and gaps in the medical equipment maintenance management process so that the necessary steps can be taken. It also can help managers and engineers to assess maintenance status and provide solutions and interventions for the decision makers and policymakers to improve its.

\section{Methods}

The present study was a multi-methods study in four stages. In the first stage, a systematic review on data related to factors which affect the assessment of MEMM was conducted. Then, a qualitative study was designed to investigate these factors from expert view and related documents. In the end, the results of the first and second stages were combined using content analysis and the final checklist was developed.

\section{Stage 1}

A systematic search of the following databases was conducted during October 2015 in the PubMed, ProQuest, Scopus, Embase, and Web of Science. The search was updated in June 2017. Our search strategy was as follow: (("medical device"*"[Title/Abstract]) OR "medical equipment"[Title/Abstract]) AND "maintenance management"[Title/ Abstract])) [14]. At first, we extracted the items, then categorized the extracted items based on the Ministry of Health and Medical Education of Iran (MOHME) framework in each category [13]. 


\section{Stage 2}

In the qualitative step, semi-structured interviews and documents review were used for data collection. The collected data consisted of the perspectives of medical and biomedical engineers concerning factors influencing MEMM. Related documents were regulations of MEMM, MEMM guidelines and other related regulations or reports developed by MOHME. The content analysis approach (inductive and deductive) was used to analyze the data. The extracted codes were sorted into both themes and subthemes based on comparisons between similarities and differences that were categorized into 7 main themes and 22 subthemes [15].

\section{Stages 3}

In this stage, the researchers combined the extracted data from systematic review and qualitative study using a content analysis and devised the first draft of the checklist. The primary checklist was developed in the form of assessment checklists in seven dimensions (providing resources, quality control tests, preventive inspection and maintenance, database, training, service, design and implementation).

\section{Stages 4}

We sent the primary draft of checklist through a Delphi to 20 experts who had sufficient scientific and information background in the field of MEMM for assessing the validity and reliability. Of them seven experts participated in this stages and send their comments. In the first round, experts commented on the content, dimensions, writing and appearance of the primary checklist. The research team modified the primary version based on expert's comments and sends it again to experts. Eventually, the proposed checklist was finalized after approving the experts.

Acknowledgements

The current study is a part of MSc thesis in Healthcare Management, Rona Bahreini. The authors appreciate Tabriz University of Medical Sciences for its financial support.

\section{Authors' contributions}

RB conceived of the presented idea. Al and LD were in charge of overall direction and planning. RB and MAZ drafted the manuscript. $\mathrm{Al}, \mathrm{LD}, \mathrm{RB}$ and MAZ contributed to the design and implementation of the research. All the authors discussed the results and commented on the manuscript. RB and MAZ revised the manuscript based on the reviewer's comments. All the authors read and approved the final manuscript.

\section{Funding}

This study was funded by Tabriz University of Medical Sciences. This study is a part of MSc thesis that has been done with the ethical code TBZMED.REC.1394.570.

Availability of data and materials

The datasets of this study are available from the corresponding authors upon reasonable request.

\section{Declarations}

Ethics approval and consent to participate

This study is a part of MSc. thesis that has been done under the support of Tabriz University of Medical Sciences with the ethical code TBZMED.REC.1394.570

\section{Consent for publication}

All the authors confirmed the consent for publication.

\section{Competing interests}

The authors declare that they have no conflict of interest. 


\begin{abstract}
Author details
${ }^{1}$ Social Determinants of Health Research Center, Birjand University of Medical Sciences, Birjand, Iran. ${ }^{2}$ Health Economics Department, Tabriz Health Services Management Research Center, School of Management and Medical Informatics, Tabriz University of Medical Sciences, Tabriz, Iran. ${ }^{3}$ Tabriz Health Services Management Research Center, Iranian Center of Excellence in Health Management, School of Management and Medical Informatics, Tabriz University of Medical Sciences, Tabriz, Iran. ${ }^{4}$ Department of Health Sciences (HLV), Public Health Science, Mid Sweden University, Sundsvall, Sweden. ${ }^{5}$ Higher School of Public Health, Al Farabi Kazakh National University, Almaty, Kazakhstan. ${ }^{6}$ Tabriz Health Services Management Research Center, Iranian Center of Excellence in Health Management, Student Research Committee, School of Management and Medical Informatics, Tabriz University of Medical Sciences, Tabriz, Iran.
\end{abstract}

Received: 6 October 2020 Accepted: 30 December 2020

Published online: 21 May 2021

\title{
References
}

1. Oshiyama NF, Silveira AC, Bassani RA, Bassani JWM. Medical equipment classification according to corrective maintenance data: a strategy based on the equipment age. Revista Brasileira de Engenharia Biomédica. 2014;30(1):64-9.

2. Taghipour S. Reliability and maintenance of medical devices: Citeseer. University of Toronto; 2011.

3. Hamdi N, Oweis R, Zraiq HA, Sammour DA. An intelligent healthcare management system: a new approach in workorder prioritization for medical equipment maintenance requests. J Med Syst. 2012;36(2):557-67.

4. Karimi A, Mojdeh S, Mehraban MA. The effect of six sigma program on improving medical equipment management of operating rooms in one of the hospitals in Isfahan in 2016. Pharmacophore. 2017;8(6):e-1173225.

5. Kihiu J, Maranga S, Mutia D. Maintenance management of medical equipment in hospitals. Indust Eng Let. 2012;2(3):9-19.

6. Jamshidi A, Rahimi SA, Ait-kadi D, Bartolome AR. Medical devices inspection and maintenance; a literature review. In: Institute of Industrial and Systems Engineers annual conference proceedings, vol. 3895. 2014.

7. Goszczynska M, Tyszka T, Slovlc P. Risk perception in Poland: A comparison with three other countries. J Behav Decis Mak. 1991;4(3):179-93.

8. Patil PJ, Patil SP, Jaltade VG, Gupta SS. Departmental equipment maintenance system in Government Medical College. Int Arch Integr Med. 2015;2(3):79-86.

9. Alikhani P, Ganji H, Abtahi M, Vesal S, Naghdi B. Preventive maintenance of medical equipment in Alzahra Hospital, Isfahan, Iran 2013. Int J Health Syst Disaster Manag. 2013;1 (4):217.

10. Mahfoud H, El Barkany A, El Biyaali A. A hybrid decision-making model for maintenance prioritization in health care systems. Am J Appl Sci. 2016;13(4):439-50.

11. Abdo AM, Wahed MA, Sharawi A. Dynamic model for evaluation of medical devices maintenance in developing countries. Int J Appl Innov Eng Manag. 2014;3(12):146-59.

12. Chen M-F, Chu S-L, Lee J-K, Lin F-H, Tsai C-L, Kao T, et al. editors. The benefit of in-hospital clinical engineer services for medical devices maintenance. In: XIV Mediterranean conference on medical and biological engineering and computing. Cham: Springer; 2016. pp. 975-8.

13. Medical equipment maintenance management criteria of Ministry of Health and Medical Education (MoHME) of Iran. Available at: https://arums.ac.ir/imam/fa/page/7367/.

14. Bahreini R, Doshmangir L, Imani A. Affecting medical equipment maintenance management: a systematic review. J Clin Diagn Res. 2018;12(4):1-7.

15. Bahreini R, Doshmangir L, Imani A. Influential factors on medical equipment maintenance management. J Qual Maint Eng. 2019;25(1):128-43.

16. Herrera-Galán M. Management audit applied to the maintenance department in hospital facilities//Auditoría de gestión aplicada al departamento de mantenimiento en instalaciones hospitalarias. Ingeniería Mecánica. 2017;20(3):152-9.

17. Al-Mawali A, Pinto AD, Al-Hinai AT. Medical equipment and healthcare technology: health vision 2050. Biomed Instrum Technol. 2018;52(6):442-50.

18. Cuzco MAV, Parra SRV, Londoño CMG, Costales JHN. Assessment of the maintenance management in hospitals of the Ecuadorian institute of social security of Zona 3 of Ecuador. Ingenius. 2019;22:59.

19. Amerion A, Alijanzadeh M, Teymourzadeh E. Effective factors on the management of medical equipment maintenance in a military hospital: a qualitative study in Iran. EBNESINA. 2015;17(3):11-8.

20. Liu W, Shi B, Guilan L. Medical equipment maintenance management based on PDCA. Chin Med Equip J. 2015;36(5):138-9.

21. Wang B. Medical equipment maintenance: management and oversight. Synth Lect Biomed Eng. 2012;7(2):1-85.

\section{Publisher's Note}

Springer Nature remains neutral with regard to jurisdictional claims in published maps and institutional affiliations. 